\title{
DEPOSIÇÃO DE FILMES FINOS DE COBRE POR GAIOLA CATÓDICA: ANÁLISE DO CONFINAMENTO DO PLASMA EM FUNÇÃO DO AUMENTO DA ESPESSURA DA TAMPA DA GAIOLA CATÓDICA
}

\author{
Fernanda de Melo Fernandes ' \\ Igor Oliveira Nascimento ${ }^{\prime}$ \\ Rômulo Ribeiro Magalhães de Sousa ${ }^{2}$ \\ Ivan Alves de Souza ' \\ Bruno Felipe Dantas ' \\ José Cesar Augusto Queiroz ' \\ Thércio Henrique de Carvalho Costa ${ }^{3}$
}

\section{Resumo}

Nitretação a plasma é uma técnica consolidada na indústria e visa melhorar diversas propriedades de superfícies, contribuindo para a vida útil dos materiais. Porém, há algumas desvantagens, tais como, efeito de borda, tratamentos de peças com geometrias complexas, etc. Sendo assim, foi criada a Active Screen Plasma Nitriding (ASPN), conhecida como técnica da tela ativa. Esse trabalho tem como objetivo estudar a cinética de deposição de filmes finos de cobre, utilizando a técnica da gaiola catódica, na qual é uma variante da ASPN, alterando a espessura da tampa da gaiola, de onde é extraído o material para formação do filme fino. Filmes de cobre caracterizam-se como bons condutores elétricos e térmicos, justificando seu uso em microeletrônica, e segundo a U.S. Environmental Agency (EPA), existem 282 tipos de ligas de cobre bactericidas, capacitando sua utilização em ambientes estéril. As deposições foram realizadas sobre amostras de vidros, variando a tampa em 2, 4, 6, 12 e $24 \mathrm{~mm}$, mantendo-se fixos os parâmetros de gás (argônio), pressão, corrente e temperatura. Foi possível observar uma relação direta entre filmes contínuos e o aumento da espessura da gaiola, e foi obtido uma formação de filmes de cobre puro.

Palavras-chave: Deposição por plasma; Técnica da tela ativa; Filme fino de cobre.

\section{DEPOSITION OF COPPER THIN FILMS BY CATHODIC CAGE: ANALYSIS OF THE PLASMA CONFINEMENT AS A FUNCTION OF THE INCREASE OF THE CATHODIC CAGE LID THICKNESS}

\begin{abstract}
Plasma nitration is a technique consolidated in the industry and aims to improve various properties of surfaces, contributing to the useful life of the materials. However, there are some disadvantages, such as edge effect, treatments of parts with complex geometries, etc. Thus, was created the Active Screen Plasma Nitriding (ASPN), known as the active screen technique. This work has the objective of study the deposition kinetics of thin films of copper using the cathodic cage technique, in which it is a variant of the ASPN, changing the thickness of the lid of the cage, from which material is extracted forming the thin film. Copper films are characterized as good electrical and thermal conductors, justifying their use in microelectronics, and according to the U.S. Environmental Agency (EPA), there are 282 types of bactericidal copper alloys, enabling them to be used in sterile environments. The depositions were performed on glass samples, varying the lid in 2, 4, 6, 12 and $24 \mathrm{~mm}$, keeping the parameters of gas (argon), pressure, current and temperature fixed. It was possible to observe a direct relation between continuous films and the increase of the thickness of the cage, and a formation of pure copper films was obtained. Keywords: Deposition by plasma; Active Screen Plasma Nitriding (ASPN); Thin film of copper.

'Laboratório de Processamento de Materiais por Plasma - LabPlasma, Programa de Pós-graduação em Engenharia Mecânica - PPGEM, Universidade Federal do Rio Grande do Norte - UFRN, Natal, RN, Brasil. E-mail: nanda.melo_f@hotmail.com

${ }^{2}$ Laboratório de Processamento de Materiais por Plasma - LabPlasma, Departamento de Engenharia Mecânica, Universidade Federal do Piauí UFPI, Teresina, PI, Brasil.

${ }^{3}$ Laboratório de Processamento de Materiais por Plasma - LabPlasma, Departamento de Engenharia Mecânica, Universidade Federal do Rio Grande do Norte - UFRN, Natal, RN, Brasil.
\end{abstract}

2176-1523 (C) 2016 Associação Brasileira de Metalurgia, Materiais e Mineração. Publicado pela ABM. Este é um artigo de acesso aberto distribuído sob os termos da licença Creative Commons CC BY-NC-ND (Attribution-NonCommercial-NoDerivs) - https:// creativecommons.org/licenses/by-nc-nd/4.0\%. 


\section{INTRODUÇÃO}

Nitretação a plasma convencional de corrente continua, Direct Current Plasma Nitriding (DCPN), melhora várias propriedades físicas de superfícies metálicas como a dureza, resistência ao desgaste e à corrosão, que contribuem para o aumento do tempo de vida útil das amostras nitretadas. Este processo apresenta vantagens em relação a outras técnicas de nitretação por meio líquidos (sal fundido) e a nitretação a gás (amônia dissociada), por exemplo, a não emissão de poluentes, economia de energia e de tempo de tratamento. No entanto, existem algumas desvantagens como efeito do cátodo oco, efeito de borda, temperatura e arcos não uniformes, especialmente no tratamentos de amostras de geometria complexas [I,2].

Para corrigir os efeitos dispostos, várias alternativas ao processo nitretado foram criados, como o Active Screen Plasma Nitriding (ASPN), no qual as amostras são envolvidas por uma tela e submetidos a um elevado potencial catódico. Dessa forma, o plasma é formado na gaiola que funciona como cátodo e não sobre a superfície da amostra, que permanecem em potencial flutuante, posicionado em uma superfície isolante (disco de alumina) [3]. A gaiola catódica consiste em uma chapa cilíndrica vazada (corpo da gaiola) com furos de centros adjacentes de mesmo diâmetro e uma tampa circular também com furos similares [4]. Nessa configuração a gaiola funciona como cátodo na qual é aplicada a diferença de potencial em relação às paredes da câmara. Assim, o plasma forma-se sobre a gaiola e não sobre a amostra [5].

Diferentemente do processo com cátodo único, no qual as partículas pulverizadas no cátodo são direcionadas para a amostra pelo fluxo do gás e pela diferença de potencial entre a câmara e a cavidade do cátodo, na gaiola ionizante as partículas presente são forçadas a fluir através da gaiola sobre as amostras, pela introdução de conduto direcionador. Os átomos arrancados da superfície da gaiola podem se combinar com o gás reativo da atmosfera do plasma, formando compostos que se depositam na superfície do substrato, permitindo a deposição de uma camada uniforme independente da forma geométrica e das dimensões das amostras. Dessa forma a gaiola deve ser confeccionada no material do qual se deseja depositar [4-6].

Barbosa juntamente com Sousa, observaram que na utilização da gaiola catódica a espessura da camada nitretada varia inversamente com a pressão no reator para uma mesma corrente elétrica. Tal propriedade é justificada pelo livre caminho médio ser maior enquanto a pressão é menor. Assim, as partículas em média são mais rápidas e promovem colisões de maior energia, resultando em uma maior disponibilidade de elementos arrancados da gaiola, permitindo uma maior eficiência na deposição na superfície da amostra $[7,8]$.

Sousa e Nishimoto, estudou a influência da posição entre a amostra e a gaiola catódica em si, e concluíram que quanto mais próximo a amostra estiver da gaiola maior a espessura, a dureza e quantidade de nitretos no filme formado. Isto foi justificado pelo sputtering que ocorre na gaiola, de modo que quanto mais próxima da gaiola o substrato estiver, menor será a distância que os átomos arrancados da gaiola precisarão percorrer para chegar à amostra, tendo assim uma menor probabilidade de colidirem com outras espécies presentes no plasma e se dispersarem $[9,10]$.

O cobre possui alta condutividade tanto térmica como elétrica, tornando-se assim sua aplicação mais comuns em indústria automobilística, pois este se encontra nos fios, conectores, freios, rolamentos, radiadores e até mesmo no próprio motor. Por exemplo, um carro chega a possuir I,5 km de fios de cobre, podendo aumentar esse valor dependendo do tamanho do automóvel [I I].

Hoje já se conhece ação antibacteriana do cobre, e por isso já é utilizado em alguns países em locais como metrôs e hospitais. Desde 2008, a U.S. Environmental Agency (EPA) já aprovou 282 tipos de ligas de cobre antibacteriana. A intenção era diminuir contaminações por superfícies em locais de alto tráfego, diminuindo a proliferação de agentes patogênicos. De acordo com ensaios clínicos realizados na Alemanha, no Japão, no Reino Unido, nos Estados Unidos e no Chile, há claras evidências da eficácia deste material no combate à proliferação bacteriana [ $\mathrm{I} \mathrm{I}]$.

Conhecendo a importância dos filmes finos de cobre e sua aplicabilidade, foi confeccionada uma gaiola catódica de cobre para obtenção de filmes finos de cobre em uma superfície de vidro. Os filmes de Cu sobre as superfícies de vidro foram obtidos em diferentes espessuras de tampa da gaiola catódica, com objetivo de estudar o efeito da espessura da tampa da gaiola sobre a camada depositada, possibilitando também, avaliar o efeito sobre o confinamento do plasma.

O presente trabalho estuda a influência da espessura da tampa da gaiola na espessura, continuidade e composição dos filmes depositados. Para tanto se avaliou a alteração de massa das tampas e das amostras, a composição foi avaliada por Difração de raio $X$, e a continuidade foi mensurada por testes de condutividade elétrica.

\section{MATERIAIS E MÉTODOS}

As amostras utilizadas foram laminas microscópicas de vidro de tamanho $25,4 \times 76,2 \mathrm{~mm}$ com espessura del , $2 \mathrm{~mm}$, do fabricante Microscope Slides. Os substratos foram cortados com dimensões iguais de $20 \times 25 \mathrm{~mm}$, e foram nomeados de acordo com a espessura da tampa utilizada na deposição, sendo elas E0 para o vidro puro, E2, E4, E6, EI 2 e E24, para as espessuras de 2, 4, 6, I2, 24 mm respectivamente. A Figura I, a seguir, expõe o fluxograma do procedimento metodológico adotado no desenvolvimento deste trabalho.

Para a nitretação iônica com gaiola catódica, foi utilizado o mesmo equipamento de nitretação convencional. Dotado de uma fonte de tensão de corrente contínua com voltagem e corrente máximas de $1500 \mathrm{~V}$ e $2 \mathrm{~A}$, respectivamente. A câmara de vácuo cilíndrica foi confeccionada de aço inoxidável, 


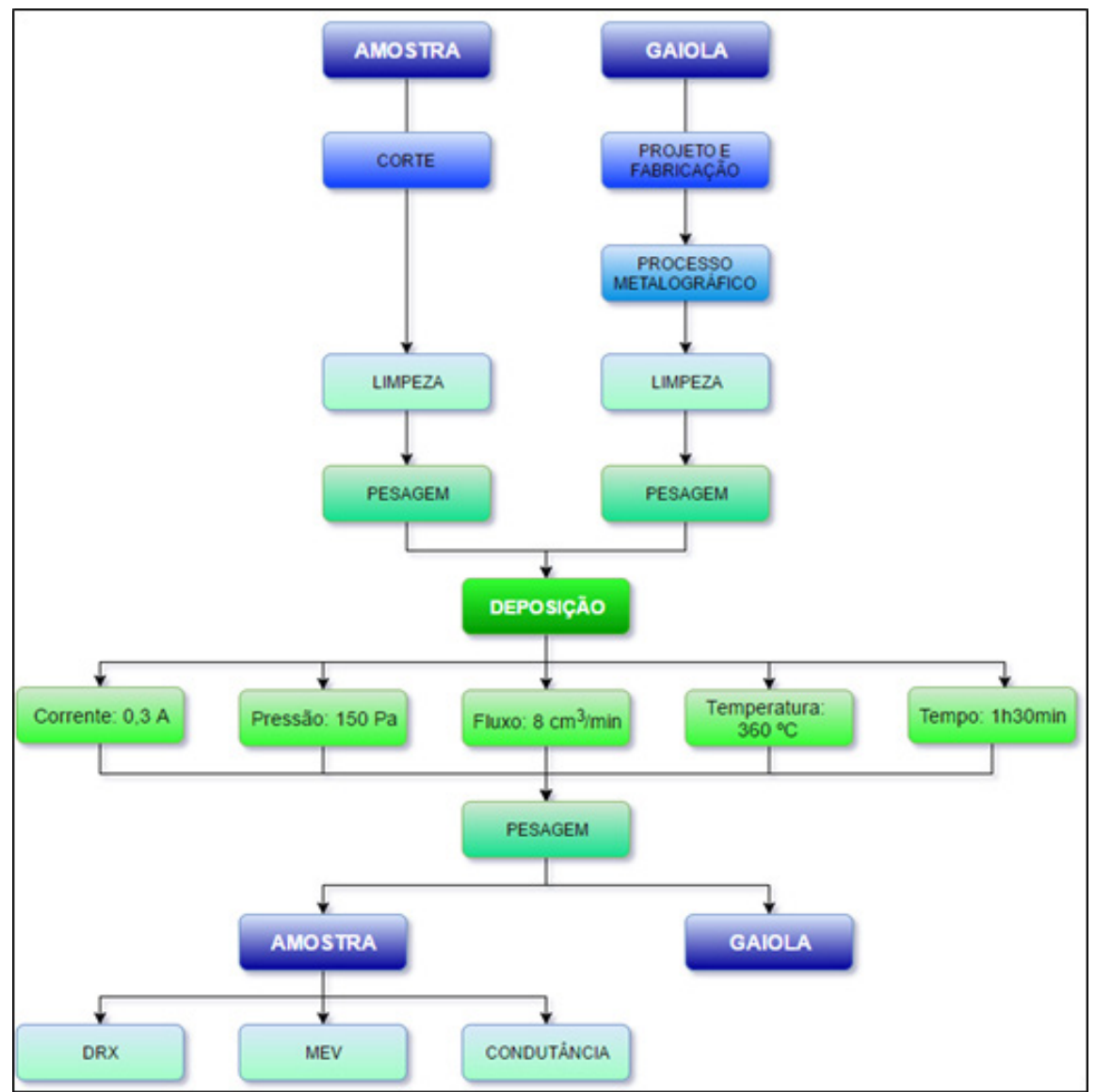

Figura I. Fluxograma do processo ASPN.
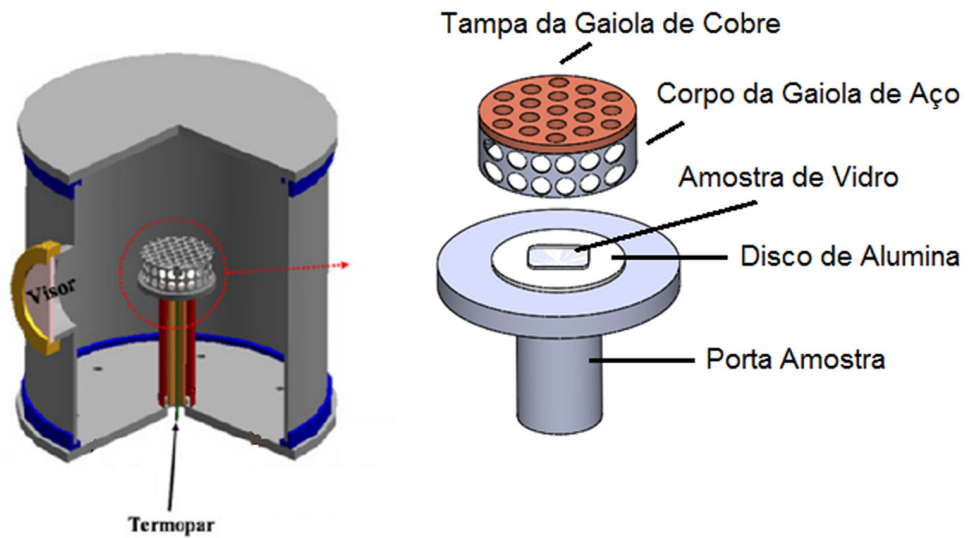

Figura 2. Esquematização da câmara de vácuo com utilização da gaiola catódica.

com $30 \mathrm{~cm}$ de diâmetro e $40 \mathrm{~cm}$ de altura. Adicionou-se um dispositivo denominado de gaiola catódica, sendo o material da tampa de cobre e seu corpo de aço inox SAE 3 I6. Tal sistema é visto na Figura 2.

Como parâmetro inicial deste trabalho se utilizou uma gaiola com espessura de $2 \mathrm{~mm}$, pois de acordo com trabalhos desenvolvidos anteriormente esta seria uma configuração ideal para deposição de filmes por gaiola catódica [7-10].
Entretanto de acordo com Mihailova, para se ter um maior aproveitamento do efeito cátodo oco, o comprimento do cátodo deve ser 3 vezes maior que o diâmetro do furo, assim variou-se a espessura da tampa de forma que se atingisse tal condição [12]. Portanto foram confeccionadas: uma tampa de $2 \mathrm{~mm}$ de espessura, uma tampa de $4 \mathrm{~mm}$ de espessura e quatro tampas de $6 \mathrm{~mm}$ de espessura, somando um total de 5 configurações distintas de tampas. $O$ diâmetro das 
tampas foi fixado em $65 \mathrm{~mm}$, já o diâmetro dos furos foi de $8 \mathrm{~mm}$, sendo eles com centro equidistante de $13 \mathrm{~mm}$, totalizando 19 furos por tampa.

A Figura 3 ilustra as dimensões da tampa da gaiola. Ressalta-se que para tratamentos onde foram precisos utilizar tampas sobrepostas, não foi visualizado nenhuma alteração no comportamento do plasma atuante nos furos das tampas, afirmando assim que, devido a perfeita sobreposição dos furos, o plasma reconheceu estes furos como um corpo vazado de espessura única.

Após fabricação, todas as tampas foram lixadas, em seguidas, as tampas foram limpas em ultrassom por 15 minutos e secas em ar quente. Após a limpeza, as tampas foram pesadas. $O$ corpo da gaiola confeccionado em aço inox SAE3 16 com furos equidistantes teve a mesma preparação que as tampas.

A gaiola foi posicionada sobre o cátodo do reator de nitretação conforme ilustrado na Figura 2. O plasma foi formado na gaiola catódica, que funcionou como cátodo (a parede da câmara era o ânodo) e não diretamente na superfície da amostra, que permaneceu em potencial flutuante, posicionada em uma superfície isolante. $O$ disco de alumina foi a superfície isolante e possui $56 \mathrm{~mm}$ de diâmetro e 2 mm de espessura.

A composição de fases foi analisada usando difração de raios-X (DRX). A varredura de raios $X$, realizou-se na configuração Braggbretano, com posição inicial igual a $25^{\circ}$ e posição final de $80^{\circ}$. A velocidade da varredura foi de $1 \%$ min. Para a aquisição dos dados utilizou-se o difratômetro de raios $X$ de alta resolução Bruker, modelo D2 Phaser. Por fim, realizou-se as medidas de condutividade dos filmes de cobre utilizado um Osciloscópio Keysight DSO I 072B - $70 \mathrm{MHz}$ - 2 canais. No osciloscópio foi medido um sinal de onda quadrada de aproximadamente $3, \mathrm{I}$ V.

\section{RESULTADOS E DISCUSSÕES}

A Figura 4 mostra o aspecto visual dos tratamentos, com a importância da formação visível a olho nu do confinamento do cátodo oco. Vale salientar que, fixou-se os parâmetros de pressão $150 \mathrm{~Pa}$, corrente $0,3 \mathrm{~A}$,

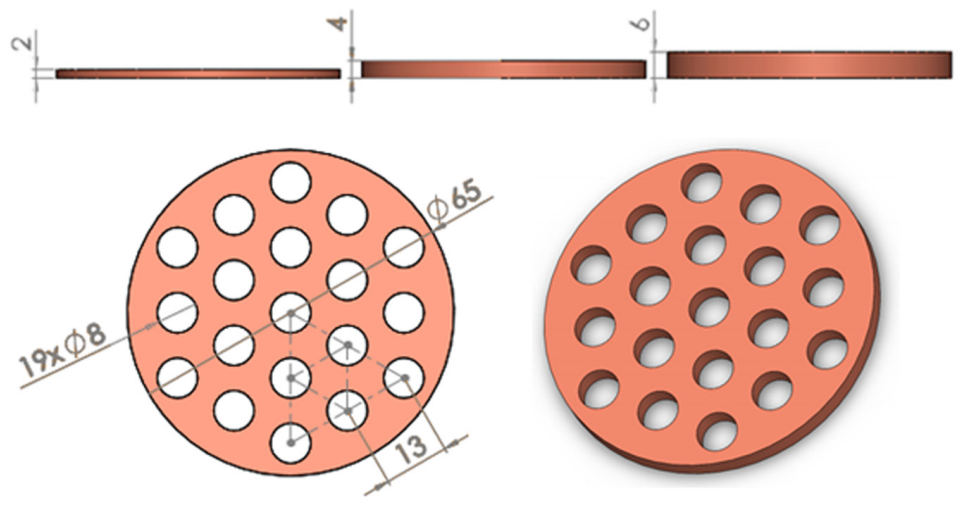

Figura 3. Representação das medidas da tampa da gaiola catódica.

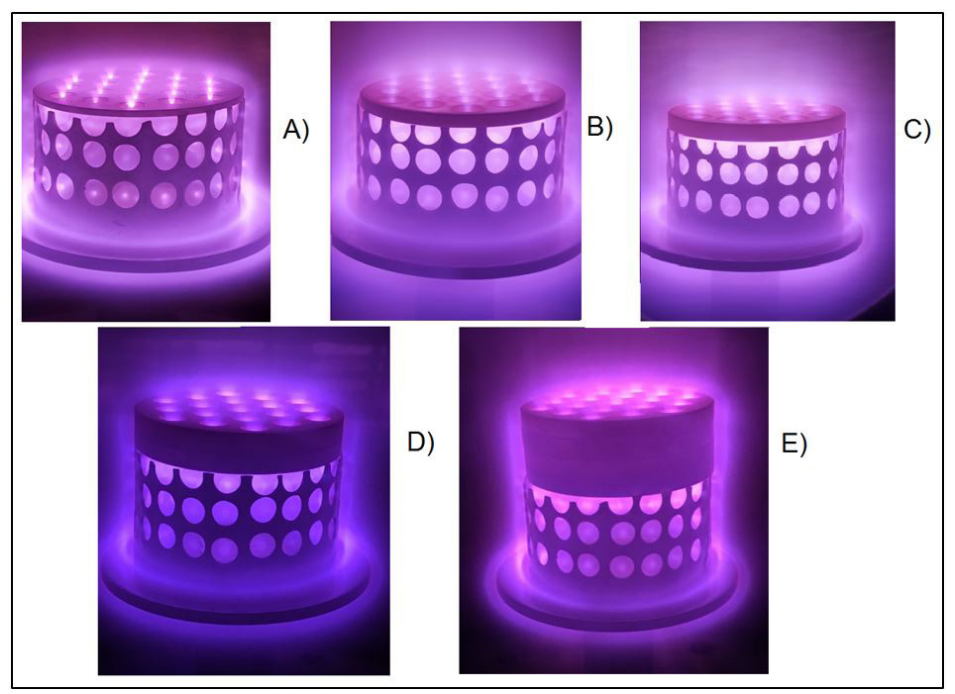

Figura 4. Deposições com o aumento progressivo da espessura das tampas de: A) E2, B) E4 C) E6, D) EI2 e E) E24. 
temperatura $360^{\circ} \mathrm{C}$, fluxo $8 \mathrm{~cm}^{3} / \mathrm{min}$ e tempo $\mathrm{h} 30 \mathrm{~min}$, variando-se apenas as espessuras das tampas. Nota-se que ocorreu confinamento do cátodo oco nos furos de todas as tampas, porém nas gaiolas $A, B$ e $C$ é visto um efeito mais intenso do confinamento, o que caracteriza como uma condição de maior eficiência na deposição dos filmes, pois quanto mais intenso o confinamento, maior será a energia de ionização e consequentemente maior o arrancamento das espécies e melhor deposição nas amostras [4-10].

As amostras foram colocadas sobre uma folha branca e logo em seguida sobre as letras do alfabeto e dispostas contra uma fonte luminosa, para evidenciar o efeito da translucides do filme, como mostrado na Figura 5 (i) e (ii), respectivamente. É possível constatar que as gaiolas que apresentaram melhor confinamento do cátodo oco, E4 e E6, foram as que apresentaram, visualmente, os filmes mais espessos, indicados na Figura 5C e 5D, respectivamente. Deduz-se que, para um maior confinamento do plasma obtém-se um maior arrancamento de espécies da tampa da gaiola e haverá melhor deposição de cobre no substrato, ou seja, obtém-se mais eficiência na deposição.
Devido a pesagem, antes e depois da deposição, tanto das amostras como das tampas (fórmulas indicada no gráfico junto a legenda), foi constatado na Figura 6 a porcentagem de massa de ambos. Nota-se que, a espessura da tampa que obteve melhor confinamento do cátodo oco e que tem menor transparência do filme, E6, é a que mais ganhou massa no caso da amostra, e a que mais perdeu massa no caso da tampa. Levando a crer que tem-se um filme mais espesso e consequentemente mais continuo na deposição com tampa de $6 \mathrm{~mm}$, devido a taxa de ionização ser maior.

$\mathrm{Na}$ Figura 7, estão ilustrados os difratogramas de raio $X$ de todas as amostras, é possível constatar picos cristalinos de cobre, principalmente nos tratamentos com tampa de espessura de 4 e $6 \mathrm{~mm}$. Também pode-se observar a presença desses picos, em menor intensidade, tanto no tratamento de tampa com espessura de $2 \mathrm{~mm}$ como no de $24 \mathrm{~mm}$, provando que os filmes também são de cobre.

As amostras E2 e E24 foram as que apresentaram menor taxa de massa e portanto menor espessura do filme enquanto o $\mathrm{E} 6$ foi o que apresentou maior ganho de massa,

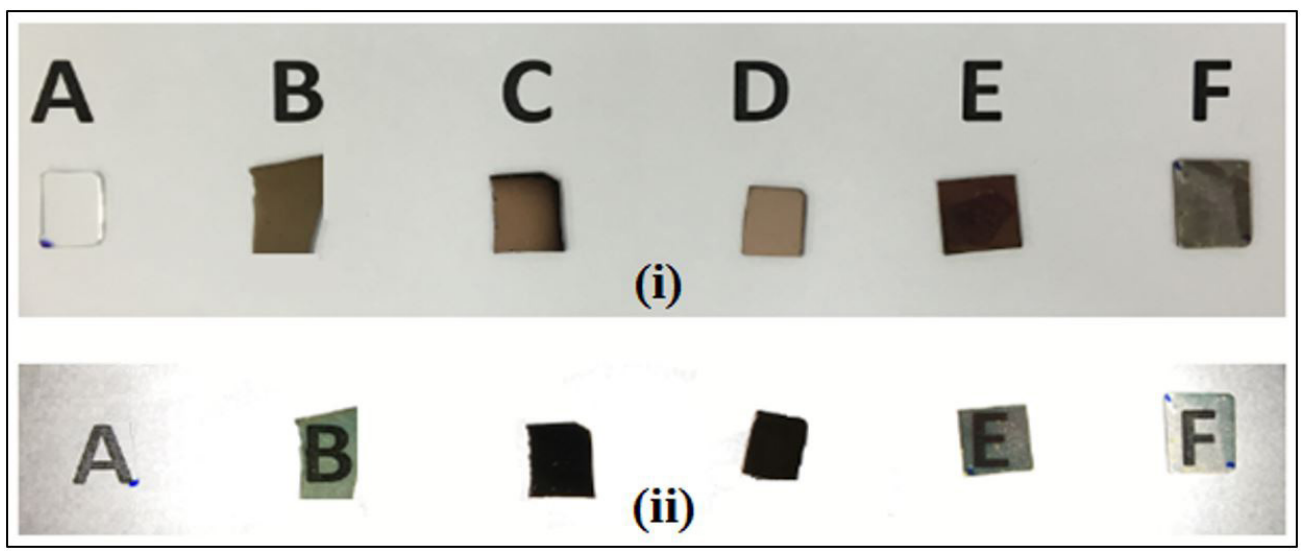

Figura 5. Análise dos filmes, sendo elas: A) E0, B) E2, C) E4, D) E6, E) EI2 e F) E24.

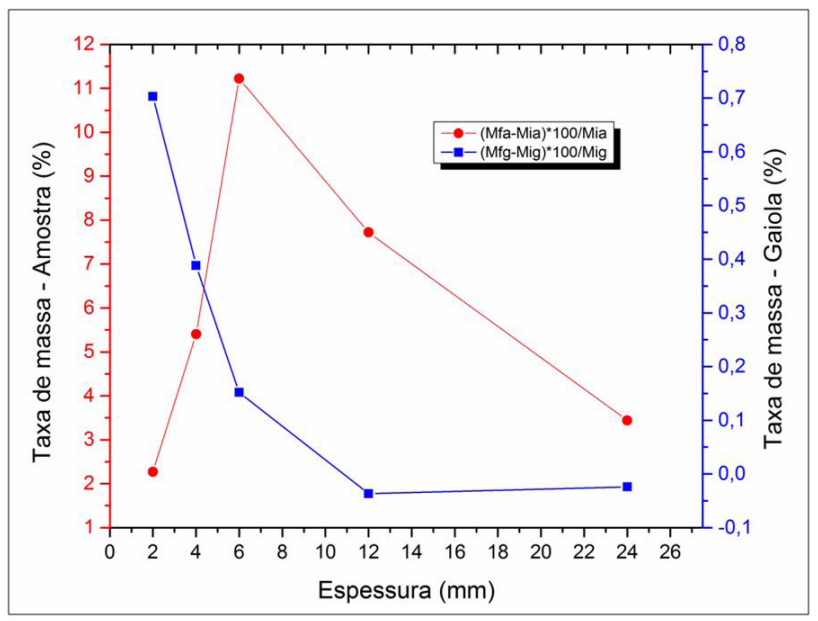

Figura 6. Taxa de massa das amostras (círculo vermelho) e das tampas da gaiola (quadrado azul).

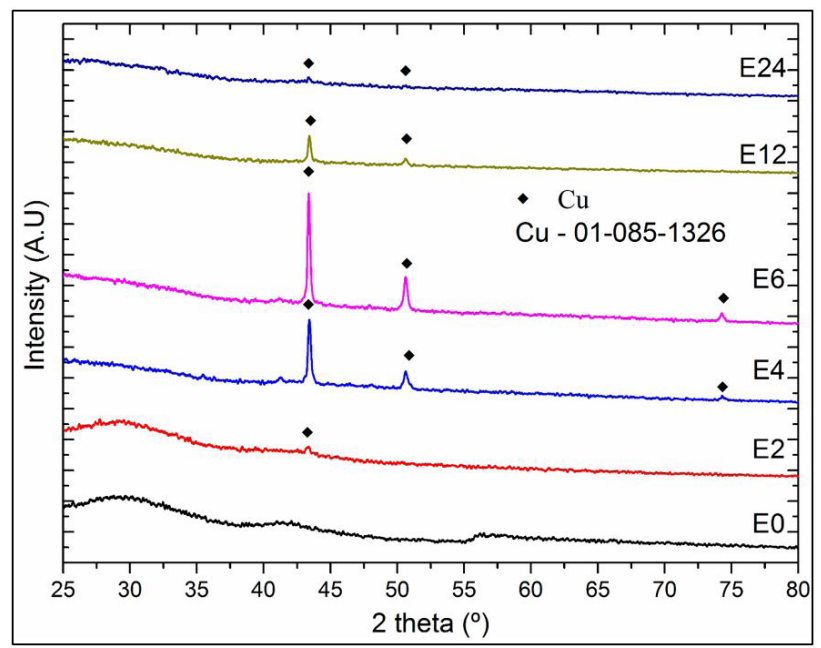

Figura 7. DRX referendado pela carta cristalográfica ICDD 085-I326. 
ou seja, quanto maior for o ganho de massa das amostras, mais filme depositado, com isso menor a translucidez e maior intensidade do pico do DRX

A fim de comprovar a eficiência na condutividade elétrica dos filmes, os mesmos foram submetidos a uma diferença de potencial de 3,12 V e como pode ser visualizado na Tabela I, apresentaram condutividade os filmes depositados com tampas de espessuras de 2, 4 e $6 \mathrm{~mm}$. Como foi visto no confinamento do cátodo oco, Figura 4, essas composições de gaiola, foram as que tiveram melhor confinamento do plasma. O filme proveniente da deposição da tampa de $6 \mathrm{~mm}$ é o mais continuo e cristalino de acordo com o ganho de massa e o pico encontrado no $\mathrm{DRX}$, consequentemente terá a melhor condutividade comparado com os demais.

\section{CONCLUSÃO}

Para todas as condições de espessura estudas, foi constatada uma presença mínima de cobre como visto no DRX, porém para uma maior certeza nas amostras E2 e E24, deve-se ser investigado, posteriormente, com técnicas de diagnósticos mais superficiais. Isto confirma o confinamento do plasma através da formação de cátodo oco nos furos da tampa e a deposição através do sputtering. O DRX também demostra que o material do corpo da gaiola não influencia no sputtering, pois não foi encontrado picos de aço inox 316.
Tabela I. Condutividade elétrica com sinal de onda quadrada de aproximadamente $3,12 \mathrm{~V}$

\begin{tabular}{ccc}
\hline Filme & Tensão aplicada & Tensão medida \\
\hline E2 & 3,12 & 3,12 \\
E4 & & 3,12 \\
E6 & & 3,12 \\
EI2 & & 0 \\
E24 & & 0 \\
\hline
\end{tabular}

A configuração da gaiola influência nos parâmetros da deposição, de modo que, quanto maior a espessura da tampa maior será sua corrente, consequentemente maior será a pressão. Justificando assim, a falta de condutividade tanto do filme derivado da deposição de $12 \mathrm{~mm}$ de espessura como também a de $24 \mathrm{~mm}$, pois seu confinamento do catodo oco não foi tão intenso e resultou em filmes translúcidos, ou seja, filme delgado e não contínuo.

A deposição proveniente da espessura da tampa da gaiola de $6 \mathrm{~mm}$ foi a que possuiu o filme mais continuo, provado tanto pelos picos cristalinos do cobre do DRX como pela relação de massa dos filmes, no qual foi o filme mais pesado. Concluindo que, os parâmetros adotados são ideias para tratamentos com essa espessura de tampa. Sendo assim, faz-se necessário a continuação dos estudos variando, além da espessura, outros parâmetro para encontrar as condições ideias para as demais espessuras de tampas, fazendo com que as deposições tornem-se mais eficientes com menores custo de tempo e energia.

\section{REFERÊNCIAS}

I Alves C, Araújo FO, Ribeiro KJB, Costa JAP, Sousa RRM, Sousa RS. Use of cathodic cage in plasma nitriding. Materials Research. 2013; I7(2):427-433.

2 Sousa RRM, Araújo FO, Ribeiro KJB, Mendes MWD, Da Costa JAP, Alves C. Cathodic cage nitriding of samples with different dimensions. Materials Science and Engineering A. 2007;465(I):223-227.

3 Sousa RM, Araújo FO, Ribeiro KJB, Sousa RS, Barbosa JCP, Alves C Jr. Nitretação iônica em gaiola catódica do aço inoxidável martensítico AISI 420. Revista Matéria. 2008; I3(I): I04-I09.

4 Daudt NF. Influência dos parâmetros de processo na deposição de nitreto de titânio por plasma em gaiola catódica [dissertação]. Natal: Universidade Federal do Rio Grande do Norte, 2012.

5 Araújo FO, Sousa RRM, Costa JAP, Alves C Jr. Deposição de filme metálico em amostras de vidro em gaiola catódica. Revista Brasileira de Aplicações de Vácuo. 2009;27(3):149-152.

6 Sousa RRM. Nitretação iônica sem efeito de borda: desenvolvimento e avaliação de uma nova técnica [dissertação]. Natal: Universidade Federal do Rio Grande do Norte, 2006.

7 Barbosa JCP. Análise por meio de Espectroscopia de Emissão Óptica das espécies ativas em nitretação iônica e gaiola catódica [dissertação]. Natal: Universidade Federal do Rio Grande do Norte, 2007.

8 Sousa RRM. Nitretação em plasma com gaiola catódica: investigação do mecanismo e estudo comparativo com a nitretação em plasma de tensão contínua [tese]. Natal: Universidade Federal do Rio Grande do Norte, 2007.

9 Sousa RRM, Araújo FO, Costa JAP, Dumelow T, Oliveira RS, Alves C. Nitriding in cathodic cage of stainless steel AISI 316: Influence of sample position. Vacuum. 2009;83(I I): I 402-I 405.

10 Nishimoto A, Nagatsuka K, Narita R, Nii H, Akamatsu K. Effect of the distance between screen and sample on active screen plasma nitriding properties. Surface and Coatings Technology. 2010;205:S365-S368. 
Fernandes et al.

II Portal Metalica. O cobre e suas aplicações [página da internet]. [acesso em 19 ago. 20 I6]. Disponível em: http:// www.metalica.com.br/pg_dinamica/bin/pg_dinamica.php?id_pag=479.

12 Mihailova D, van Dijk J, Grozeva M, Hagelaar GJM, van der Mullen JJAM. A hollow cathode discharge for laser applications: influence of the cathode length. Journal of Physics D: Applied Physics. 2010;43(14): 145203.

Recebido em: 29 Nov. 2016

Aceito em: 4 Jul. 2017 